\title{
REVIEW
}

\section{Epidermal growth factor receptor and bladder cancer}

\author{
A J Colquhoun, J K Mellon
}

Postgrad Med J 2002;78:584-589

Muscle-invasive bladder cancer is a disease which causes significant morbidity and mortality. The two main forms of treatment for this disease include radical cystectomy and radical radiotherapy, but five year survival after treatment remains low at $40 \%$. Many clinical and molecular risk factors have been shown to be associated with poor prognosis. One such factor is the expression of epidermal growth factor receptor (EGFR), which is overexpressed by many epithelial tumours, including bladder cancers. There are several methods of inhibiting the activity of EGFR and it may be that use of an anti-EGFR therapy, in combination with more conventional treatment, provides a method of improving the prognosis for muscle-invasive bladder cancer.

See end of article for authors' affiliations

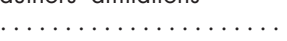

Correspondence to: Professor J K Mellon, Clinical Sciences Unit, Leicester General Hospital, Gwendolen Road, Leicester LE5 4PW, UK; jkm7@le.ac.uk

Submitted 17 May 2002 Accepted 22 July 2002
B ladder cancer is the fifth commonest male and seventh commonest female malignancy in England and Wales with an annual incidence of 10500 cases and accounts for approximately 5000 deaths per annum..$^{1-3}$ The term bladder cancer is used to describe collectively tumours of urinary bladder urothelial origin which exhibit diverse biological behaviour, ranging from relatively benign to highly malignant. Thus, bladder cancer can be without serious clinical consequences for the patient who has an isolated "superficial" bladder tumour and dies many years later of an unrelated cause, or it can be a lethal disease resulting in death a short time after presentation. Eighty per cent of bladder cancers are "superficial" at presentation in that they have not invaded into the detrusor muscle ( Ta, Tl tumours). The remaining 20\% are "muscle-invasive", extending through the detrusor muscle (T2-4 tumours) and such tumours carry a much graver prognosis (see fig 1 ).

The natural history of bladder cancer is dependent on the stage and grade of the initial tumour. For patients whose initial tumour is nonmuscle-invasive the prognosis is good. At five years, $50 \%$ of patients will remain recurrence free, $20 \%$ will have experienced one recurrence, and the remaining $30 \%$ will have had multiple recurrences. ${ }^{4}$ Of those patients who experience recurrence, $50 \%-70 \%$ of recurrent tumours are of similar histological grade and stage as the primary tumour. ${ }^{4}$ Factors predictive of tumour recurrence include presence of recurrent tumour at the three month check cystoscopy, increasing tumour stage and grade, increasing tumour size, tumour multifocality, presence of carcinoma in situ, and positive urine cytology ( see box 1)..$^{6-10}$ In
$20 \%-40 \%$ of patients whose non-muscle-invasive tumours recur, progression to muscle-invasive bladder cancer occurs (see fig 2). ${ }^{11-13}$ Given the poor prognosis of muscle-invasive bladder cancer, much work has been undertaken to determine clinical and molecular prognostic markers predictive of progression in non-muscle-invasive bladder cancer. Clinical factors predictive of progression include presence of recurrent tumour at three month cystoscopy, increasing tumour stage and grade, increasing tumour size, carcinoma in situ, and tumour multifocality. ${ }^{7813}$ Many molecular markers predictive of tumour progression have been studied including deletion or expression of mutated forms of the tumour-suppressor genes, p53 and retinoblastoma, and expression of the proto-oncogene, c-erbB-1. The literature regarding these molecular markers is large and, in general, opinion is divided. p53 has been shown by some to be predictive of tumour progression, ${ }^{14}$ while other authors dispute this. ${ }^{1617}$ Deletion or expression of a mutated form of the retinoblastoma gene is associated with tumour progression ${ }^{18} 19$ as is overexpression of the protein product of the c-erbB-1 proto-oncogene, epidermal growth factor receptor (EGFR) (see box 1). ${ }^{20-22}$

The treatment of bladder cancer is dependent on the presenting tumour's grade and stage. Nonmuscle-invasive tumours are treated by transurethral resection with or without subsequent intravesical chemotherapy or immunotherapy. In view of its poorer prognosis, the treatment of muscleinvasive tumours is more radical. The two main therapeutic options available for tumours confined to the bladder are radical cystectomy or radical radiotherapy, but the five year survival after either regimen remains poor at $40 \% .^{23-27}$ The prognosis for patients with muscle-invasive bladder cancer is dependent on a number of clinical factors. Increasing tumour stage and grade, solid tumour morphology, low haemoglobin levels, the presence of positive pelvic lymph nodes, and the presence of ureteric obstruction are associated with a subsequent poor prognosis. ${ }^{2628-31}$

The challenge to the modern urologist is twofold: firstly, to detect the small but significant proportion of patients with non-muscle-invasive bladder cancer who will progress to muscleinvasive disease and secondly, to improve the prognosis of patients with muscle-invasive bladder cancer.

Abbreviations: EGF, epidermal growth factor; EGFR, epidermal growth factor receptor; HB-EGF, heparin-binding EGF-like factor; TGF- $\alpha$, transforming growth factor-alpha 


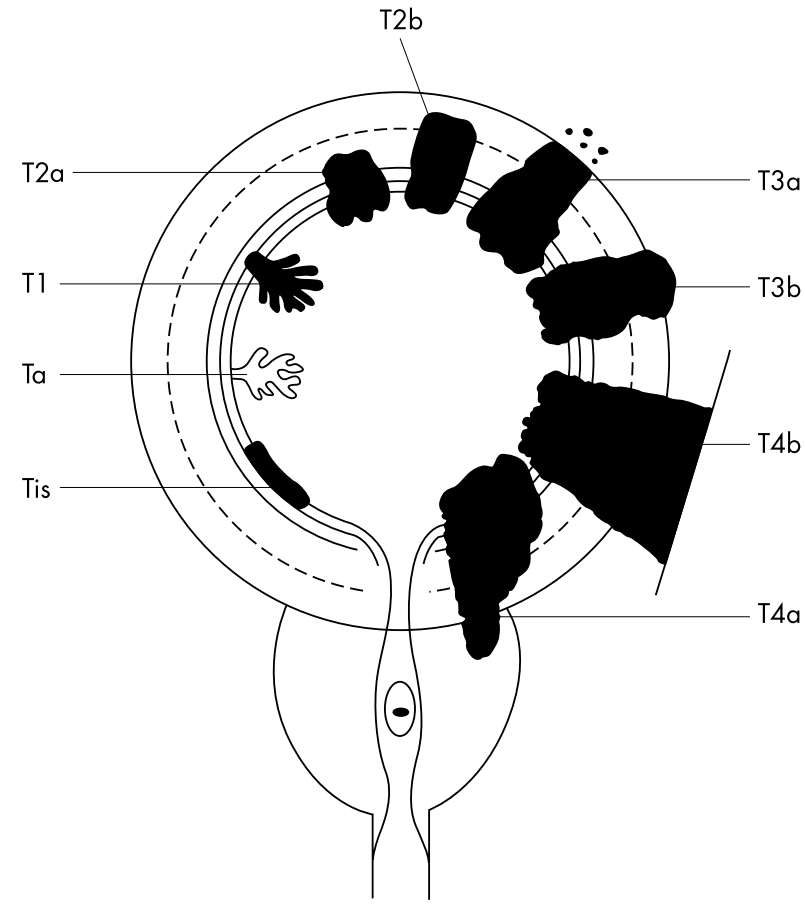

Figure 1 T staging of bladder cancer. Tis, carcinoma in situ; $\mathrm{Ta}$, tumour involves mucosa only; $\mathrm{Tl}$, tumour invades through lamina propria; T2a, tumour invades into superficial detrusor muscle; $\mathrm{T} 2 \mathrm{~b}$, tumour invades into deep detrusor muscle; T3a, tumour microscopically invades perivesical tissue; $\mathrm{T} 3 \mathrm{~b}$, tumour macroscopically invades perivesical tissue and forms extravesical mass; T4a, tumour invading prostate/uterus/vagina; T4b, tumour fixed to pelvic wall.

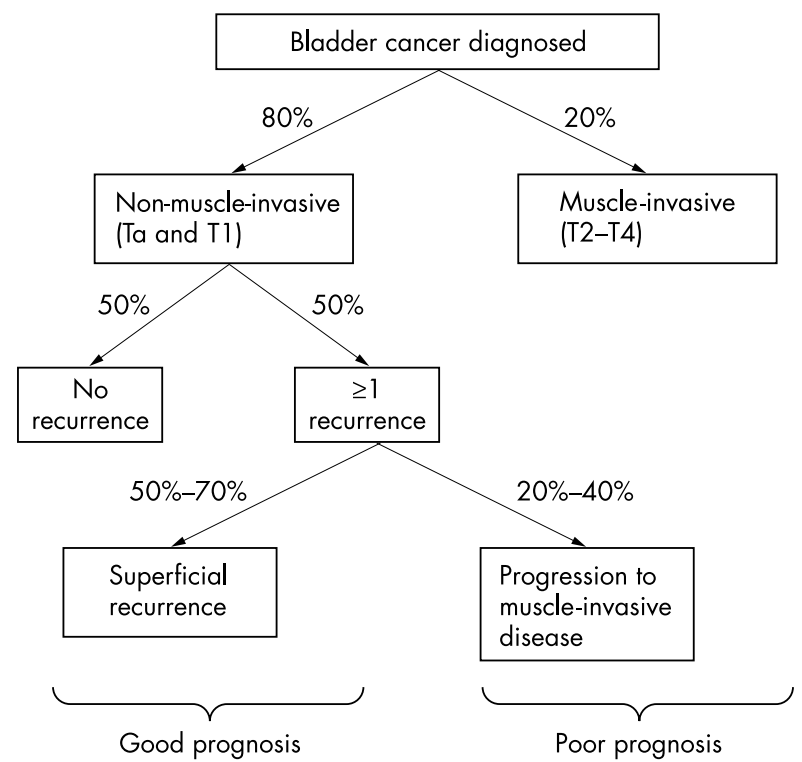

Figure 2 Natural history of bladder cancer.

\section{EPIDERMAL GROWTH FACTOR RECEPTOR FAMILY}

The epidermal growth factor receptor (EGFR) is a member of the tyrosine kinase receptor family, a group of receptors which are all encoded by the c-erbB oncogenes. There are four known c-erbB oncogenes whose transcription produces a variety of protein products that play a physiological role in coordinated cell growth and tissue repair (see fig 3). Pathological expression of these proto-oncogenes is associated with the loss of coordination of cell growth that typifies malignancy. For example, the overexpression of c-erbB-2 has been

\section{Box 1: Factors predictive of superficial tumour} recurrence and progression

- Recurrent tumour at three month check cystoscopy.

- Increasing tumour stage and grade.

- Increasing tumour size.

- Tumour multifocality.

- Presence of carcinoma in situ (recurrence, progression).

- Positive urine cytology (recurrence).

- Deletion/mutation of retinoblastoma gene (progression).

- Expression of c-erbB-1/EGFR (progression).

- ?Expression of p53 (progression).

\section{Box 2: Factors predictive of poor prognosis for}

\section{muscle-invasive bladder cancer}

- Increasing tumour stage and grade.

- Solid tumour morphology.

- Low haemoglobin levels.

- Ureteric obstruction.

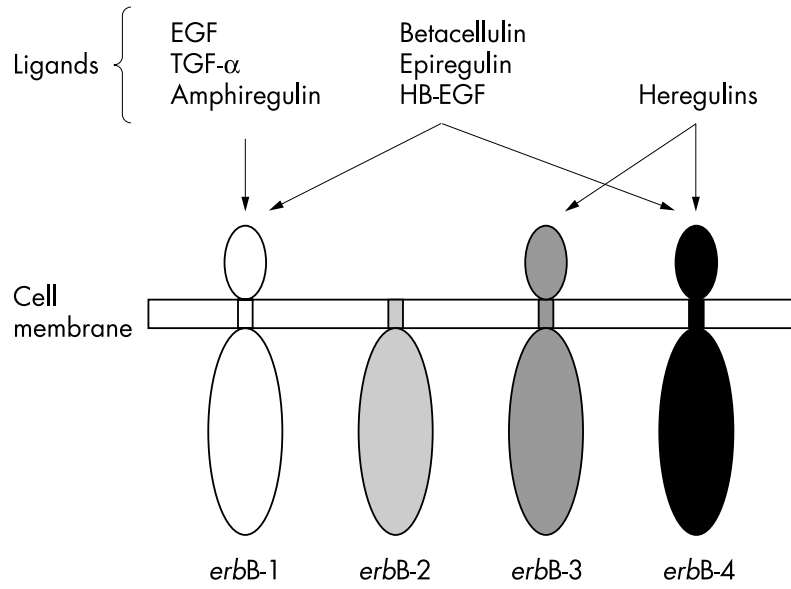

Figure 3 The c-erbB family of receptors and their activating ligands. EGF, epidermal growth factor; HB-EGF, heparin-binding EGF-like factor; TGF- $\alpha$, transforming growth factor-alpha.

associated with poor prognosis in patients with advanced breast cancer. ${ }^{32}$ However, in patients with bladder cancer, overexpression of c-erbB-2 has less prognostic significance. ${ }^{33}{ }^{34}$ Numerous studies have determined that expression of the c-erb B-1 proto-oncogene is associated with poor prognosis in patients with bladder cancer. ${ }^{20} 2235-37$

Epidermal growth factor was first identified and purified from the submaxillary glands of mice by Cohen in the 1960s, in his search for nerve stimulating growth factors. ${ }^{38}$ It was not, however, until 1984 that the EGFR was sequenced and cloned on chromosome $7 .^{39}{ }^{40}$ EGFR is the protein product of the c-erb B-1 proto-oncogene and is a $170 \mathrm{kDa}$ protein that consists of three distinct structural parts (see fig 4). The extracellular component forms the ligand binding region that is activated by one of several ligands (epidermal growth factor (EGF), transforming growth factor-alpha (TGF- $\alpha$ ), amphiregulin, betacellulin, heparin-binding EGF-like factor (HB-EGF) and epiregulin) (see fig 3). ${ }^{41}$ The transmembrane component is a short single stretch of 27 amino acids that traverses the cell membrane to reach the intracellular component of the receptor. The intracellular component consists of two separate domains; adjacent to the cell membrane is a catalytic domain with tyrosine kinase activity and contiguous with this is the autophosphorylation domain..$^{42}$ Activation of EGFR by one of its respective ligands leads to formation of both homodimers 


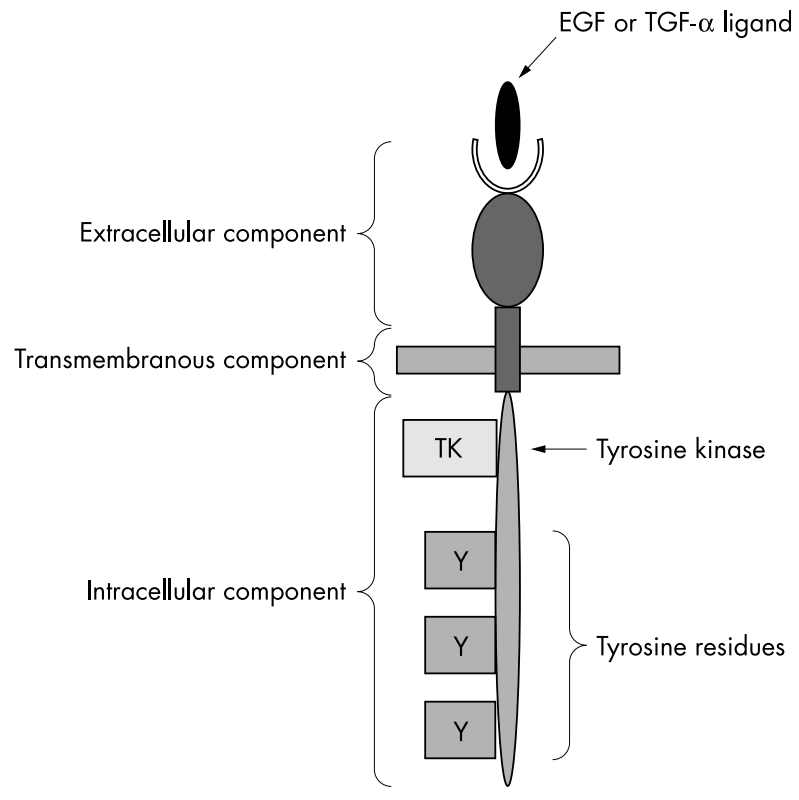

Figure 4 Epidermal growth factor receptor.

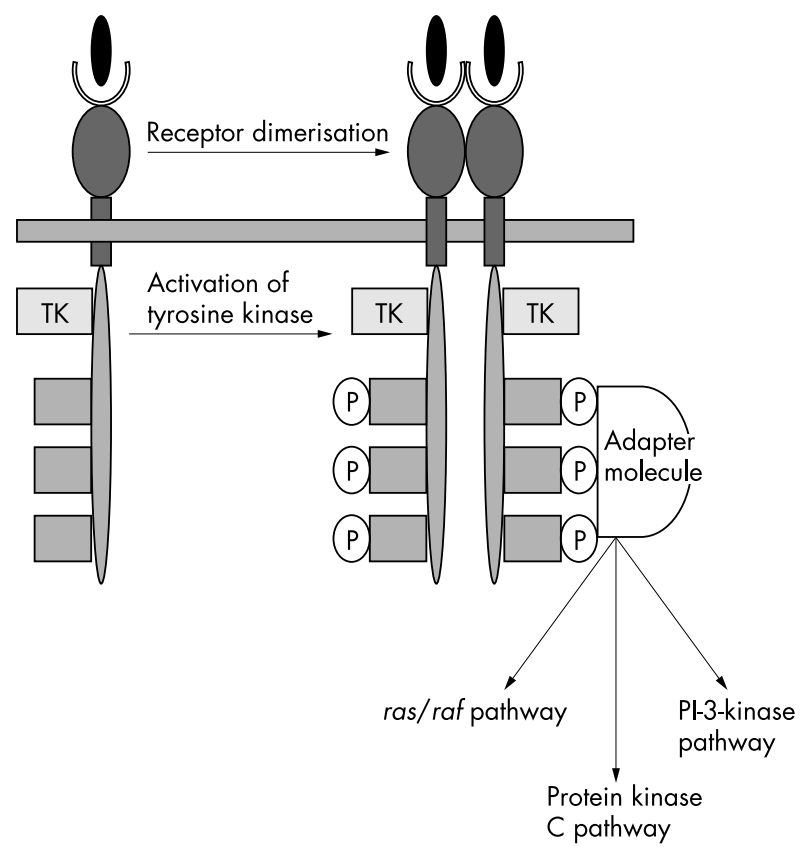

Figure 5 Activation of the EGFR. PI-3-K, phosphatidylinositol-3-kinase.

(with other EGFR) and heterodimers (with other members of the c-erbB family). ${ }^{42}{ }^{43}$ This conformational change leads to phosphorylation of the tyrosine residues located within the autophosphorylation domain. These phosphotyrosines in turn phosphorylate other intracellular proteins that contain src homologous domains ( $\mathrm{SH} 2$ and $\mathrm{SH} 3$ ). These intracellular proteins include phospholipase $\mathrm{C} \gamma$, ras associated GTPase activating protein and phophatidylinositol-3-kinase. ${ }^{44-46}$ Phosphorylation of these intracellular proteins stimulates the ras/raf, phosphatidylinositol-3-kinase and protein kinase C pathways, which ultimately lead to increased nuclear transcription and subsequent cellular proliferation (see fig 5).

\section{EGFR AND BLADDER CANCER}

As outlined above, pathological expression of EGFR leads to uncontrolled cell proliferation. It also results in increased ang-

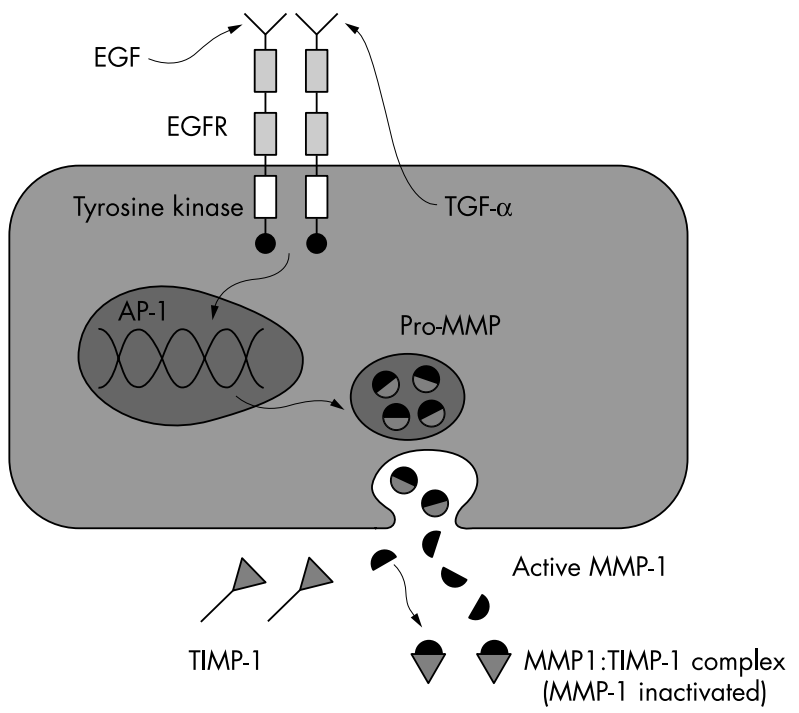

Figure 6 Potential mechanism linking EGFR to invasion and metastasis. AP-1, activator protein-1; MMP, matrix metalloproteinase TGF- $\alpha$, transforming growth factor-alpha; TIMP, tissue inhibitor of metalloproteinase.

Box 3: Incidence of EGFR positivity in epithelial tumours

- Non-small cell lung cancer: $40 \%-80 \%$

- Colorectal cancer: $25 \%-77 \%$.

- Prostate cancer: $40 \%$.

- Ovarian cancer: $35 \%-70 \%$

- Advanced gastric cancer: $33 \%$

- Pancreatic cancer: $30 \%-50 \%$.

- Breast cancer: $15 \%-30 \%$

- Bladder cancer: $50 \%$.

iogenesis and reduced apoptosis, processes necessary for continuing malignant growth. ${ }^{41}$ EGFR is known to be overexpressed by many epithelial tumours including non-small cell lung, colorectal, gastric, pancreatic, ovarian, and breast cancers (see box 3). ${ }^{35}$ Overexpression of EGFR in bladder cancer has been widely reported, ${ }^{202236} 37$ and several studies have shown EGFR positivity to be associated with high tumour stage, tumour progression, and poor clinical outcome. ${ }^{202247}$ The mechanism by which EGFR expression is associated with poor prognosis is not entirely clear, although there is some evidence linking EGFR stimulated activation of activator protein-1 transcription factor with induction of matrix metalloproteinase activity (see fig 6 ). ${ }^{48}$

\section{ACTIVATION OF EGFR BY RADIOTHERAPY}

Recent work has shown that EGFR activity is stimulated by ionising radiation (radiotherapy). ${ }^{49-51}$ This upregulation of EGFR activity is effected by the autocrine activity of radiation-induced TGF- $\alpha$ release. ${ }^{52}$ The upregulation of EGFR activity via radiation may lead to cellular proliferation. Such stimulation of cellular proliferation by radiotherapy may allow repopulation of cells to occur between fractions of radiotherapy accounting for the radioresistance seen in certain tumours. In vivo work using malignant glioma cells by Lammering et al has elegantly shown that inhibition of EGFR by transfection of a dominant-negative EGFR (inactive EGFR) and subsequent application of irradiation leads to a 1.8 -fold tumour radiosensitisation effect. ${ }^{53}$ Current work at the University of Leicester is assessing the response of muscleinvasive bladder cancers to radiotherapy, in relation to a tumour's EGFR status. 


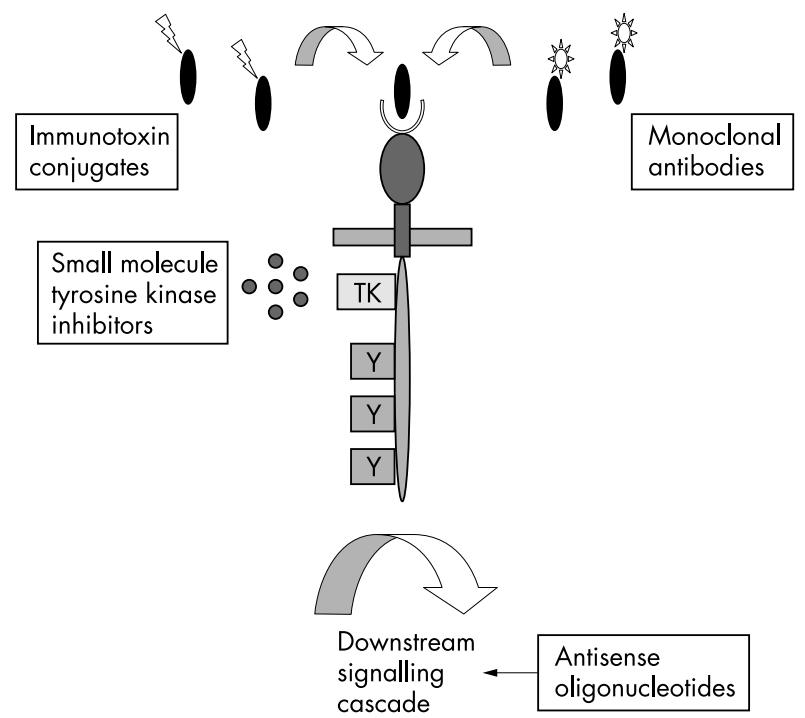

Figure 7 Methods of inhibiting EGFR activity.

\section{MANIPULATION OF EGFR ACTIVITY}

Given that EGFR overexpression is associated with poor prognosis and possible poor response to treatment, it follows that inhibition of EGFR activity may be a way of improving the prognosis for patients with bladder cancer. There are several ways in which EGFR activity can be inhibited including use of small molecule tyrosine kinase inhibitors (for example, ZD 1839, Astra Zeneca, Macclesfield, UK), monoclonal antibodies against EGFR (for example, IMC-C225, ImClone, New York, USA), immunotoxin conjugates, and antisense oligonucleotides (see fig 7).$^{41}$ To date the most studied methods of inhibition are small molecule tyrosine kinase inhibitors and monoclonal antibodies.

ZD 1839 is administered orally and has been shown to be well tolerated in phase I testing involving patients with a range of EGFR expressing malignancies (including breast, prostate, colorectal, and head and neck cancers). ${ }^{54}$ IMC-C225 is administered intravenously and has also been found to be well tolerated in phase I testing in patients with breast, bladder, prostate, and colorectal cancer. ${ }^{55}$ Both these therapies have been shown to have additive effects in vitro when used in conjunction with other conventional chemotherapeutic and radiotherapeutic treatments. ${ }^{557} \mathrm{ZD} 1839$ is now being tested in a multicentre phase III trial in conjunction with carboplatin/paclitaxel in the treatment of advanced non-small cell lung cancer and IMC-C225 has entered phase III testing in the treatment of head and neck cancer.

As well as acting to improve treatment of primary tumours, the potential exists for anti-EGFR therapies to treat metastatic disease. Work by Sainsbury et al has shown that, in breast cancer, metastatic lesions are more likely to express EGFR than primary tumours. ${ }^{58}$ Work by Bue et al in bladder cancer metastases has shown a positive correlation between the EGFR status of primary bladder tumours and associated metastases. ${ }^{59}$ By targeting therapies at inhibition of EGFR not only would it be possible to attempt to improve prognosis in the treatment of primary EGFR expressing tumours but it may also be possible to selectively target EGFR expressing metastases, irrespective of the primary tumour's EGFR status.

\section{CONCLUSION}

Bladder cancer is a prevalent disease that causes substantial morbidity and mortality. Despite the continued refinement of surgical techniques-namely, radical cystectomy-the prognosis of muscle-invasive bladder cancer has remained unchanged for the past 30 years with five year survival
Box 4: Key references

- Neal DE, Sharples L, Smith K, et al. The epidermal growth factor receptor and the prognosis of bladder cancer. Cancer 1990;65:1619-25.

- Mellon JK, Wright C, Kelly P, et al. Long-term outcome related to EGFR status in bladder cancer. J Urol 1995;153:919-25.

- Gullick WJ. Prevalence of aberrant expression of the epidermal growth factor receptor in human cancers. $\mathrm{Br}$ Med Bull 1991;47:87-98.

- Dent P, Reardon DB, Park JS, et al. Radiation-induced release of TGF $\alpha$ activates the epidermal growth factor receptor and MAPK pathway in carcinoma cells, leading to increased proliferation and protection from radiationinduced cell death. Mol Biol Cell 1999;10:2493-506.

- Lammering G, Valerie K, Lin PS, et al. Radiosensitization of malignant glioma cells through overexpression of dominantnegative epidermal growth factor receptor. Clin Cancer Res $2001 ; 7: 682-90$.

remaining disappointingly low at $40 \%$. Increased understanding of the molecular basis of bladder cancer progression, recurrence, and metastasis has led to identification of EGFR as a significant prognosticator in both non-muscle-invasive and muscle-invasive bladder cancer. The knowledge that EGFR expressing tumours are associated with poor prognosis has led to the development of several strategies to inhibit EGFR activity. Phase I and II testing of anti-EGFR therapies have shown promising results and the results of phase III testing of small molecule tyrosine kinase inhibitors and anti-EGFR monoclonal antibodies, either as monotherapies, or in combination with more conventional chemotherapeutic and radiotherapeutic treatment regimens are eagerly awaited. Pending the outcome of these studies subsequent testing of anti-EGFR therapies in patients with bladder cancer may provide evidence of a realistic treatment option to improve the prognosis for these patients.

\section{MULTIPLE CHOICE QUESTIONS (TRUE (T)/FALSE (F); ANSWERS AT END OF REFERENCES)}

Q1. Epidermal growth factor receptor is overexpressed by the following tumours:

(A) Adenocarcinoma of the breast

(B) Osteosarcoma

(C) Squamous cell carcinoma of the head and neck

(D) Leiomyoma

Q2. The following statements are true with regard to non-muscle-invasive bladder cancer:

(A) Progression occurs in $50 \%-70 \%$ of cases

(B) Increasing tumour grade and stage are predictive of recurrence

(C) Overexpression of c-erbB-2 is a risk factor for progression

(D) Multifocality is a risk factor for tumour recurrence

Q3. Deletion/mutation of the following genes is associated with non-muscle-invasive tumour progression:

(A) Retinoblastoma

(B) c-erbB-1

(C) $\mathrm{H}$-ras

(D) c-erbB-2

Q4. The following are risk factors for non-muscle-invasive tumour recurrence:

(A) Increasing age

(B) Low haemoglobin levels 
(C) High tumour grade

(D) Previous tumour recurrence

Q5. Epidermal growth factor receptor:

(A) Is encoded on chromosome 17

(B) Can form heterodimers with other members of the c-erbB receptor family

(C) Stimulation results in cellular proliferation

(D) Is frequently over expressed in bladder cancer

Q6. Survival from muscle-invasive bladder cancer is worse in:

(A) Patients undergoing radical radiotherapy as opposed to radical cystectomy

(B) Patients with high tumour stage

(C) Patients with ureteric obstruction

(D) Older patients

\section{ACKNOWLEDGEMENTS}

The authors would like to acknowledge the Royal College of Surgeons of England and Cancer Research UK for the financial support of Alexandra Colquhoun

\section{Authors' affiliations}

A J Colquhoun, J K Mellon, University Division of Urology, Leicester General Hospital, Gwendolen Road, Leicester, UK

\section{REFERENCES}

1 Office of National Statistics. StatBase: cancer: incidence rates per 100,000 population 1998 by age and sex. London: ONS.

2 Office of National Statistics. StatBase: cancer: number of new cases 1998 by age and sex. London: ONS

3 Cancer Research Campaign. Fact sheet 9.1, bladder cancer. London: CRC, 1997.

4 Fitzpatrick JM, West $A B$, Butler MR, et al. Superficial bladder tumours (stages pTa, grade 1 and 2): the importance of recurrence pattern following initial resection. J Urol 1986;135:920-2.

5 Greene LF, Hanash KA, Farrow GM. Benign papilloma or papillary carcinoma of the bladder? J Urol 1973;110:205-7.

6 Parmar MKB, Freedman LS, Hargreave TB, et al. Prognostic factors for recurrence and follow-up policies in the treatment of superficial bladder cancer: report from the British Medical Research Council Subgroup on Superficial Bladder Cancer (Urological Cancer Working Party). J Urol 1989;142:284-8.

7 Heney NM, Nocks BN, Daly JJ, et al. Ta and T1 Bladder cancer: location, recurrence and progression. Br J Urol 1982;54:152-7.

8 Kurth KH, Denis L, Bouffioux C, et al. Factors affecting recurrence and progression in superficial bladder tumours. Eur J Cancer 1995;31:1840-6.

9 Dalesio O, Schulman CC, Sylvester R, et al. Prognostic factors in superficial bladder tumours. A study of the European Orgnisation for Research on Treatment of Cancer: Genitourinary Tract Cancer Cooperative group. J Urol 1983;129:730-3.

10 Jakse G, Loidl W, Sceber G, et al. Stage T1, grade 3 transitional cell carcinoma of the bladder: an unfavourable tumor? J Uro 1987; 137:39-43.

11 Tut VM, Hildreth AN, Kumar M, et al. Does voided urine cytology have biological significance? Br J Urol 1998;82:655-9.

12 Abel PD, Hall RR, Williams G. Should PT1 transitional cell cancers of the bladder still be classified as superficial? Br J Urol 1988;62:235-9.

13 Lutzeyer W, Rubben H, Dahm H. Prognostic parameters in superficial bladder cancer: an analysis of 315 cases. J Urol 1982;127:250-2.

13a Althausan AF, Prout GR, Daly JJ. Non-invasive papillary carcinoma of the bladder associated with carcinoma in situ. J Urol 1976;116: 575-80.

14 Sarkis AS, Dalbagni G, Cordon-Cardo C, et al. Nuclear overexpression of p53 protein in transitional cell bladder carcinoma: a marker for disease progression. J Natl Cancer Inst 1993;85:53-9.

15 Lipponen PK. Over-expression of p53 nuclear oncoprotein in transitional cell bladder-cancer and its prognostic value. Int J Cancer 1993:53:365-70.

16 Gardiner RA, Walsh MD, Allen V, et al. Immunohistological expression of p53 in primary $\mathrm{PT} 1$ transitional cell bladder cancer in relation to tumour progression. Br J Urol 1994;73:526-32.

17 Vet JA, Bringuier PP, Poddighe PJ, et al. p53 mutations have no additional prognostic value over stage in bladder cancer. Br J Cancer 1994:70:496-500.

18 Cordon-Cardo C, Wartinger D, Petrylak D, et al. Altered expression of the retinoblastoma gene product: prognostic indicator in bladder cancer. J Natl Cancer Inst 1992;84:1251-6.

19 Xu HJ, Cairns P, Hu SX, et al. Loss of RB protein expression in primary bladder cancer correlates with loss of heterozygosity at the RB locus and tumor progression. Int J Cancer 1993;53:781-4.
20 Neal DE, Sharples L, Smith K, et al. The epidermal growth factor receptor and the prognosis of bladder cancer. Cancer 1990;65:1619-25.

21 Lipponen P, Eskelinen M. Expression of epidermal growth factor receptor in bladder cancer as related to established prognostic factors, oncoprotein (c-erbB-2, p53) expression and long-term prognosis. $\mathrm{Br} \mathrm{J}$ Cancer 1994;69:1120-5.

22 Mellon JK, Wright C, Kelly P, et al. Long-term outcome related to EGFR status in bladder cancer. J Urol 1995;153:919-25.

23 Pearse HD, Reed RR, Hodges CV. Radical cystectomy for bladder cancer. J Urol 1978;119:216-18.

24 Skinner DG, Lieskovsky G. Contemporary cystectomy with pelvic node dissection compared to preoperative radiation therapy plus cystectomy in the management of invasive bladder cancer. J Urol 1984;131:1069-72.

25 Goffinet DR, Schneider M, Glatstein EJ, et al. Bladder cancer: results of radiation therapy in 384 patients. Radiology 1975;117:149-53.

26 Gospodarowicz MK, Hawkins NV, Rawlings GA, et al. Radical radiotherapy for muscle invasive transitional cell carcinoma of the bladder: failure analysis. J Urol 1989;142:1448-53.

27 Duncan W, Quilty PM. The results of a series of 963 patients with transitional cell carcinoma of the urinary bladder primarily treated by radical megavoltage X-ray therapy. Radiother Oncol 1986;7:299-310.

28 Quilty PM, Kerr GR, Duncan W. Prognostic indices for bladder cancer: an analysis of patients with transitional cell carcinoma of the bladder primarily treated by radical megavoltage X-ray therapy. Radiother Oncol 1986;7:311-21.

29 Mameghan H, Fisher R. Invasive bladder cancer. Prognostic factors and results of radiotherapy with and without cystectomy. Br J Urol 1989;63:251-8.

30 Shipley WU, Rose MA, Perrone TL, et al. Full-dose irradiation for patients with invasive bladder carcinoma: clinical and histological factors prognostic of improved survival. J Urol 1985;134:679-83.

31 Pryor JP. Factors influencing the survival of patients with transitional cell tumours of the urinary bladder. Br J Urol 1973;45:586-92.

32 Jukkola $A$, Bloigu R, Soini $Y$, et al. c-erbB-2 positivity is a factor for poor prognosis in breast cancer and poor response to hormonal or chemotherapy treatment in advanced disease. Eur J Cancer $2001 \cdot 37: 347-54$

33 Lee SE, Chow NH, Chi YC, et al. Expression of c-erbB-2 protein in normal and neoplastic urothelium: lack of adverse prognostic effect in human urinary bladder cancer. Anticancer Res 1994;14:1317-24.

34 Mellon JK, Lunec J, Wright C, et al. C-erbB-2 in bladder cancer: molecular biology, correlation with epidermal growth factor receptors and prognostic value. J Urol 1996;155:321-6.

35 Nicholson RI, Gee JMW, Harper ME. EGFR and cancer prognosis. Eur J Cancer 2001;37:S9-15.

36 Neal DE, Marsh C, Bennett MK, et al. Epidermal growth factor receptors in human bladder cancer: comparison of invasive and superficial tumours. Lancet 1985;i:366-8.

37 Chow NH, Liu HS, Lee El, et al. Significance of urinary epidermal growth factor and its receptor expression in human bladder cancer. Anticancer Res 1997; 17:1293-6.

38 Cohen S. The epidermal growth factor. Cancer 1983;51:1787-91.

39 Ullrich A, Coussens L, Hayflick JS, et al. Human epidermal growth factor receptor cDNA sequence and abherrant expression of the amplified gene in A431 epidermoid carcinoma cells. Nature 1984;309:418-25.

40 Kondo I, Shimizu N. Mapping of the human gene for epidermal growth actor receptor (EGFR) on the p13 leads to q22 region of chromosome 7 Cytogenet Cell Genet 1983;35:9-14.

41 Wells $\mathbf{A}$. The epidermal growth factor receptor (EGFR) - a new target in cancer therapy. Signal 2000;1:4-11.

42 Gullick WJ. Prevalence of aberrant expression of the epidermal growth factor receptor in human cancers. Br Med Bull 1991;47:87-98.

43 Wada T, Qian XL, Greene MI. Intermolecular association of the p185 neu protein and EGF receptor modulates EGF receptor function. Cell 1990;61:1339-47.

44 Carpernter G, Cohen S. Epidermal growth factor receptor. J Biol Chem 1990;265:7709-12.

45 Pelicci G, Lanfrancone L, Grignani F, et al. A novel transforming protein (SHC) with an $\mathrm{SH} 2$ domain is implicated in mitogenic signal transduction. Cell 1992;70:93-104.

46 Lowenstein EJ, Daly RJ, Batzer AG, et al. The SH2 and SH3 domain-containing protein GRB2 links receptor tyrosine kinases to ras signalling. Cell 1992;70:431-42.

47 Nguyen PL, Swanson PE, Jaszcz W, et al. Expression of epidermal growth factor receptor in invasive transitional cell carcinoma of the urinary bladder: a multivariate survival analysis. Am J Clin Pathol 1994;101:166-76.

48 Nutt JE, Mellon JK, Qureshi K, et al. Matrix metalloproteinase-1 is induced by epidermal growth factor in human bladder tumour cell lines and is detectable in the urine of patients with bladder tumours. $\mathrm{Br} \mathrm{J}$ Cancer 1998;78:215-20.

49 Kavanagh BD, Lin PS, Chen P, et al. Radiation-induced enhanced proliferation of human squamous cancer cells in vitro: a release from inhibition by epidermal growth factor. Clin Cancer Res 1995; 1: 1557-62.

50 Schmidt-Ullrich RK, Valerie K, Fogleman B, et al. The radiation-induced autophosphorylation of epidermal growth factor receptor in human malignant mammary and squamous epithelial cells. Radiat Res $1996 ; 145: 81-5$

51 Schmidt-Ullrich RK, Mikkelsen RB, Dent $\mathrm{P}$, et al. Radiation-induced proliferation of human A431 squamous carcinoma cells is dependent on EGFR tyrosine phosphorylation. Oncogene 1997;15:1191-7. 
52 Dent $\mathbf{P}$, Reardon DB, Park JS, et al. Radiation-induced release of TGF $\alpha$ activates the epidermal growth factor receptor and MAPK pathway in carcinoma cells, leading to increased proliferation and protection from radiation-induced cell death. Mol Biol Cell 1999;10:2493-506.

53 Lammering G, Valerie K, Lin PS, et al. Radiosensitization of malignant glioma cells through overexpression of dominant-negative epidermal growth factor receptor. Clin Cancer Res 2001;7:682-90.

54 Ferry D, Hammond L, Ranson M, et al. Intermittent oral ZD 1839 (Iressa), a novel epidermal growth factor receptor tyrosine kinase inhibitor (EGFR-TKI) shows evidence of good tolerability and activity: final results from a phase 1 study. (36th Annual Meeting of the American Society of Clinical Oncology (ASCO), New Orleans, 20-23 May 2000.) Proc Am Soc Clin Oncol 2000; 19:3a (Abst 5E).

55 Baselga J, Pfiste D, Cooper MR, et al. Phase 1 studies of anti-epidermal growth factor receptor chimeric antibody C225 alone and in combination with cisplatin. J Clin Oncol 2000;18:904-14.

56 Cardiello F, Caputo R, Bianco R, et al. Antitumor effect and potentiation of cytotoxic drugs activity in human cancer cells by ZD 1839 (Iressa), an epidermal growth factor receptor-selective tyrosine kinase inhibitor. Clin Cancer Res 2000;6:2053-63

57 Williams KJ, Telfer BA, Stratford IJ, et al. ZD 1839 ("Iressa"), a specific oral epidermal growth factor receptor-tyrosine kinase inhibitor, potentiates radiotherapy in a human colorectal cancer xenograft model. Br J Cancer 2002;86:1157-61.

58 Sainsbury JRC, Farndon JR, Sherbet GV, et al. Epidermal growth factor receptors and oestrogen receptors in human breast cancer. Lancet 1985;i:364-6.

59 Bue P, Wester K, Sjostrom A, et al. Expression of epidermal growth factor receptor in urinary bladder cancer metastases. Int J Cancer 1998;76: 189-93.

\section{ANSWERS}

Q1. (A) T, (B) F, (C) T, (D) F. Q2. (A) F, (B) T, (C) F, (D) T. Q3.

(A) T, (B) F, (C) F, (D) F. Q 4. (A) F, (B) F, (C) T, (D) T. Q5. (A)

F, (B) T, (C) T, (D) T. Q6. (A) F, (B) T, (C) T, (D) F.

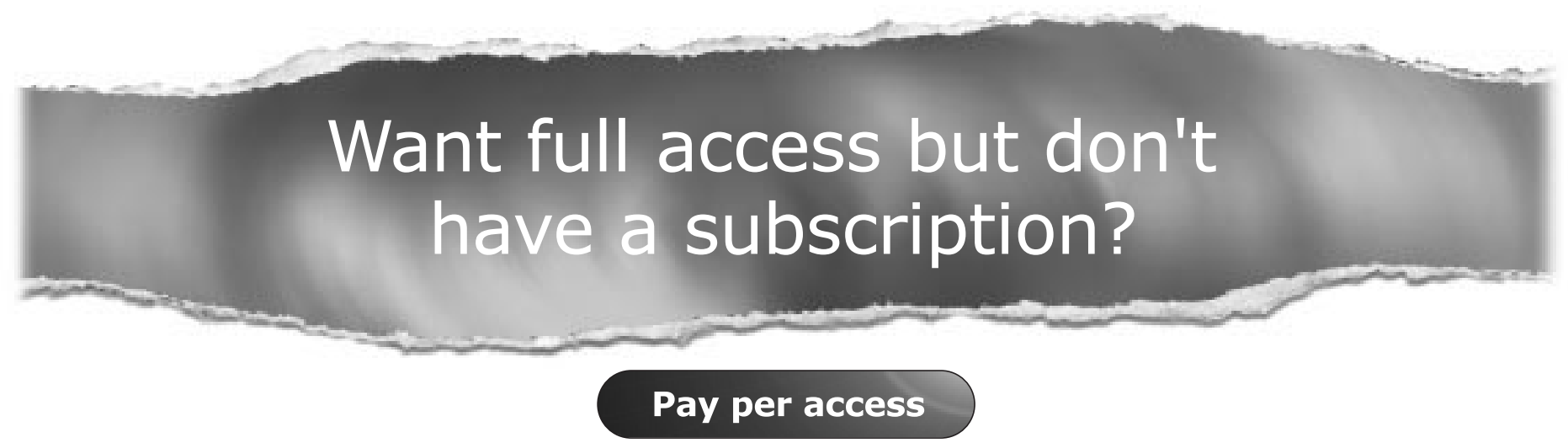

For just US $\$ 25$ you can have instant access to the whole website for 30 days. During this time you will be able to access the full text for all issues (including supplements) available. You will also be able to download and print any relevant pdf files for personal use, and take advantage of all the special features Postgraduate Medical Journal online has to offer. 